\title{
Modeling Laser and e-Beam Generated Plasma-Plume Experiments Using LASNEX
}

D.D.-M. Ho

December 1, 1999

U.S. Department of Energy

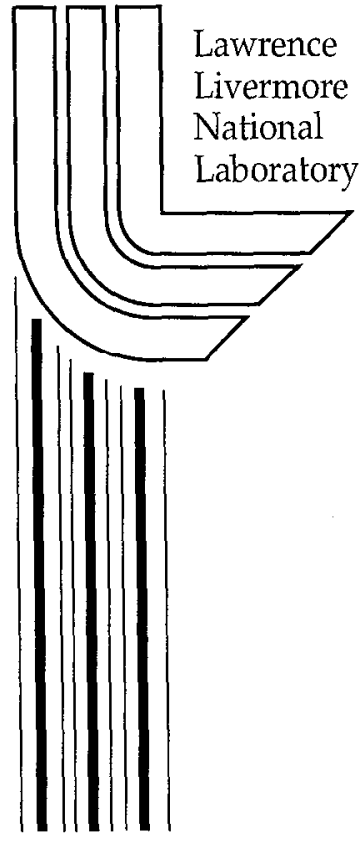




\section{DISCLAIMER}

This document was prepared as an account of work sponsored by an agency of the United States Government. Neither the United States Government nor the University of California nor any of their employees, makes any warranty, express or implied, or assumes any legal liability or responsibility for the accuracy, completeness, or usefulness of any information, apparatus, product, or process disclosed, or represents that its use would not infringe privately owned rights. Reference herein to any specific commercial product, process, or service by trade name, trademark, manufacturer, or otherwise, does not necessarily constitute or imply its endorsement, recommendation, or favoring by the United States Government or the University of California. The views and opinions of authors expressed herein do not necessarily state or reflect those of the United States Government or the University of California, and shall not be used for advertising or product endorsement purposes.

Work performed under the auspices of the U.S. Department of Energy by the University of California Lawrence Livermore National Laboratory under Contract W-7405-Eng-48.

This report has been reproduced

directly from the best available copy.

Available to DOE and DOE contractors from the Office of Scientific and Technical Information

P.O. Box 62, Oak Ridge, TN 37831

Prices available from (423) 576-8401

http://apollo.osti.gov/bridge/

Available to the public from the

National Technical Information Service

U.S. Department of Commerce 5285 Port Royal Rd., Springfield, VA 22161

http://www.ntis.gov/

\section{OR}

Lawrence Livermore National Laboratory

Technical Information Department's Digital Library

http://www.llnl.gov/tid/Library.html 


\title{
Modeling Laser and e-Beam Generated Plasma-Plume Experiments Using LASNEX
}

by

Darwin D.-M. Ho

\begin{abstract}
Summary
The hydrodynamics code LASNEX is used to model the laser and ebeam generated plasma-plume experiments. The laser used has a wavelength of $1 \mu \mathrm{m}$ and the FWHM spot size is $1 \mathrm{~mm}$. The total laser energy is $160 \mathrm{~mJ}$. The simulation shows that the plume expands at a velocity of about $6 \mathrm{~cm} / \mu \mathrm{s}$. The e-beam generated from the Experimental Test Accelerator (ETA) has 5.5 $\mathrm{MeV}$ and FWHM spot size ranges from 2 to $3.3 \mathrm{~mm}$. From the simulations, the plasma plume expansion velocity ranges from about 3 to $6 \mathrm{~mm} / \mu \mathrm{s}$ and the velocity increases with decreasing spot size. All the simulation results reported here are in close agreement with experimental data.
\end{abstract}

\section{Description of the LASNEX Simulations and Discussion of the Results}

We have performed simulations to model the laser and e-beam generated plasma-plume experiments. In this memo, we present the simulation of the target expansion using the radiation hydrodynamics code LASNEX. The typical target in the experiment is made of tantalum with a density of $16.6 \mathrm{~g} / \mathrm{cm}^{3}$ and a thickness of $1 \mathrm{~mm}$. The laser used to generate the plasma plume has a wavelength of $1 \mu \mathrm{m}$. The Gaussian pulse has a FWHM pulse length of $10 \mathrm{~ns}$. The FWHM spot size is $1 \mathrm{~mm}$ and the total laser energy is $160 \mathrm{~mJ}$. The electron beam from the ETA has kinetic energy of $5.5 \mathrm{MeV}$ and a current of $1.7 \mathrm{kA}$. The pulse length is $70 \mathrm{~ns}$. The rise and fall time of the pulse are $10 \mathrm{~ns}$ and the central flat-top portion has a 50 ns duration. The FWHM spot size ranges from 2 to $3.3 \mathrm{~mm}$.

(I) Simulation of the plasma plume generated by laser illumination

The laser used to generate the plasma plume has a wavelength of $1 \mu \mathrm{m}$. The pulse shape is Gaussian with FWHM pulse length of $10 \mathrm{~ns}$ and the FWHM spot size is $1 \mathrm{~mm}$. The total laser energy is $160 \mathrm{~mJ}$. The plot of the laser energy vs time is shown in Fig. 1.

Because the laser intensity is relatively weak and the skin depth is very shallow, the thickness of the outermost zone of the mesh used for this 
simulation must be very thin, e.g. in the order of several nanometer. The configuration of the mesh is shown in Fig. $2 a$ and the enlarged plot of the mesh near the vacuum-target interface is shown in Fig. 2b. In Fig. $2 b$, the thickness of the outermost zoncs of the mesh is too thin to be resolved in the figure.

The density contours are shown in Fig. 3a and the temperature distribution and the average ionization $\mathrm{Z}$ of the plasma plume at $20 \mathrm{~ns}$ are shown in Figs. $3 b$, respectively. Note that the electron-ion collision time $\tau_{\mathrm{ei}}$ is substantially shorter than the laser pulse duration. Therefore, $\mathrm{T}_{\mathrm{i}}=\mathrm{T}_{\mathrm{e}}$.

The leading-edge expansion velocity vs time is plotted in Fig. 4. At about $100 \mathrm{~ns}$, the leading edge expansion is about $90 \%$ of the terminal velocity of about $6 \mathrm{~cm} / \mu \mathrm{s}$, which is within the range of uncertainty of the experimentally measured velocity by Houck (Ref. 1).

Note that the leading edge velocity is less than $6 \mathrm{~cm} / \mu \mathrm{s}$ if the velocity is obtained by dividing the distance expanded by the time in Fig. $3 \mathrm{~b}$. This is because the expansion velocity in early time is less than 6 $\mathrm{cm} / \mu \mathrm{s}$.

(II) Simulation of the plasma plume as a function of e-beam spot size

In this set of simulations, we have chosen three different e-beam spot radii --- 2.0, 2.5, and $3.2 \mathrm{~mm}$. The energy deposited into the target by the e-beam is simulated by putting an energy source in the target. The initial configuration of the mesh is shown in Fig. 5. In order to speed up the simulation, we only simulate the left-half of the target. The electron beam is assumed to come in from the left.

The energy deposited vs time in the left-half of the slab is shown in Fig. 6a. The leading edge expansion velocity vs time, for the calculation with $2.0 \mathrm{~mm}$ spot radius, is shown in Fig. 6b. The temperature distribution and the $\mathrm{Z}$ contours of the plasma plume are shown in Figs. $7 \mathrm{a}$ and $7 \mathrm{~b}$, at 70 and $300 \mathrm{~ns}$, respectively. At the end of the pulse at $70 \mathrm{~ns}$, the maximum temperature inside the target is a little above $3 \mathrm{eV}$.

To measure the plume velocity, the forward Faraday cup for the plume velocity measurement is located at a distance of $25 \mathrm{~cm}$ from the target at an angle of $30^{\circ}$ from the axis (Ref. 2). Therefore, the time it takes for the leading edge of the plume to reach the Faraday cup is in the order of tens of microseconds. This time is greater than the transit time (about $250 \mathrm{~ns}$ ) for the leading edge of the plume to increase from zero to the maximum velocity as shown in Fig. 6b. Therefore, the velocity measured using the Faraday cup should be close to the maximum velocity shown in Fig. $6 \mathrm{~b}$ multiplied by $\cos 30^{\circ}$. The leading-edge expansion velocities, at an angle of $30^{\circ}$ from the beam axis, obtained from the simulation, are 
plotted vs the inverse of spot size in Fig. 8. The experimentally measured expansion velocities by Houck (Ref. 2) are also plotted here. The simulation result shows that the leading edge plasma velocity ranges from about 3.3 to $6.0 \mathrm{~mm} / \mu \mathrm{s}$ as the spot radius decreases from 3.2 to 2.0 $\mathrm{mm}$. This figure shows that the simulation and the experimental results are in good agreement.

\section{Conclusion}

The simulation results of the plasma plume velocities for the experiments described here are in good agreement with the experimentally measured data. This good agreement established the fact that LASNEX is a valuable tool for simulating laser and e-beam generated plasma plumes.

\section{References:}

(1) T. Houck, personal communication, Lawrence Livermore National Laboratory, 1999.

(2) T. Houck, et al. , "Faraday Cup Measurements of the Plasma Plume Produced at an X-Ray Converter" LINAC98. 


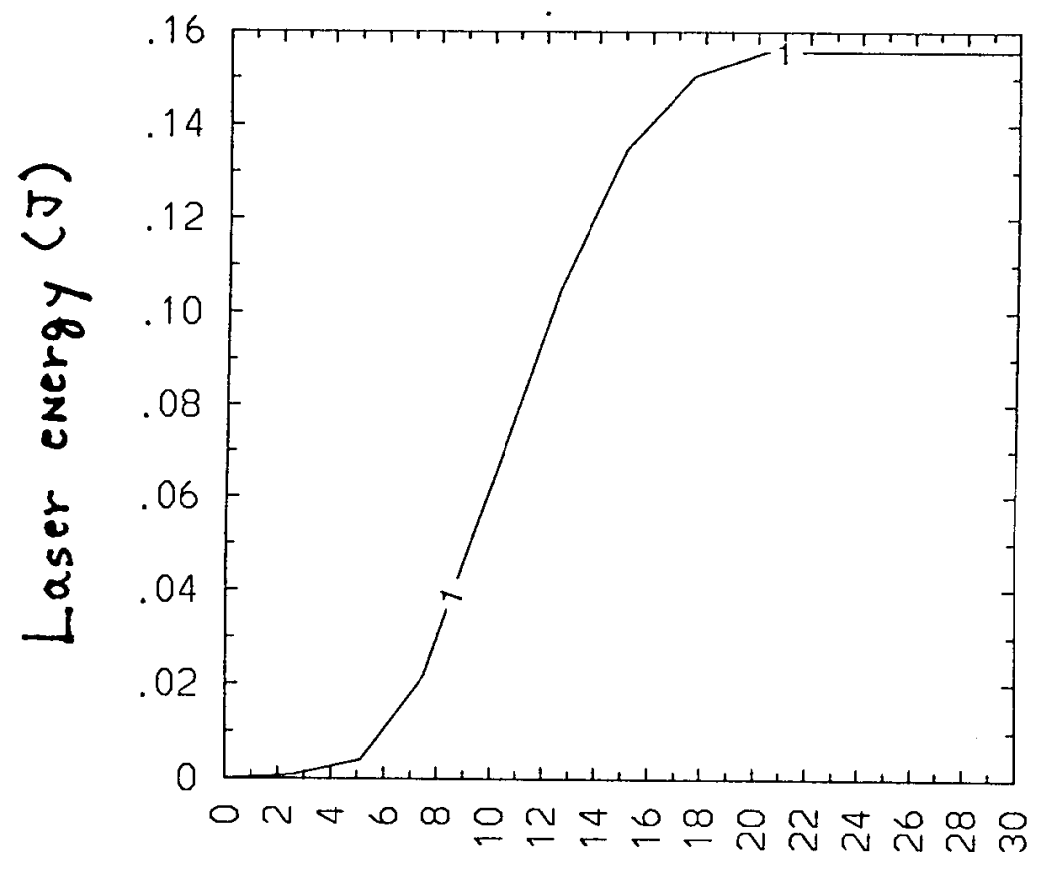

Time (ns)

Fig. 1 
Mesh Configuration

(a)

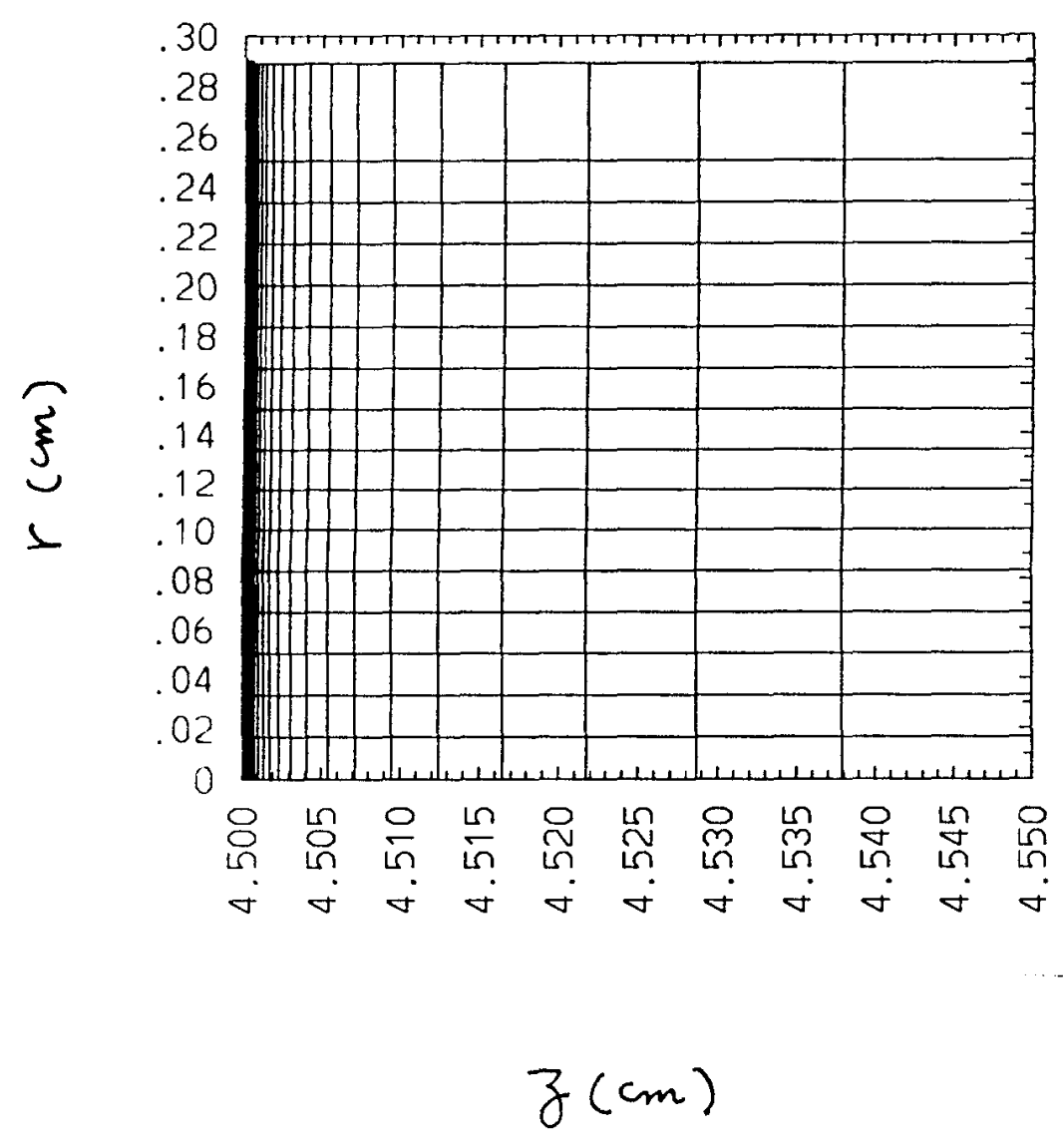

(b)

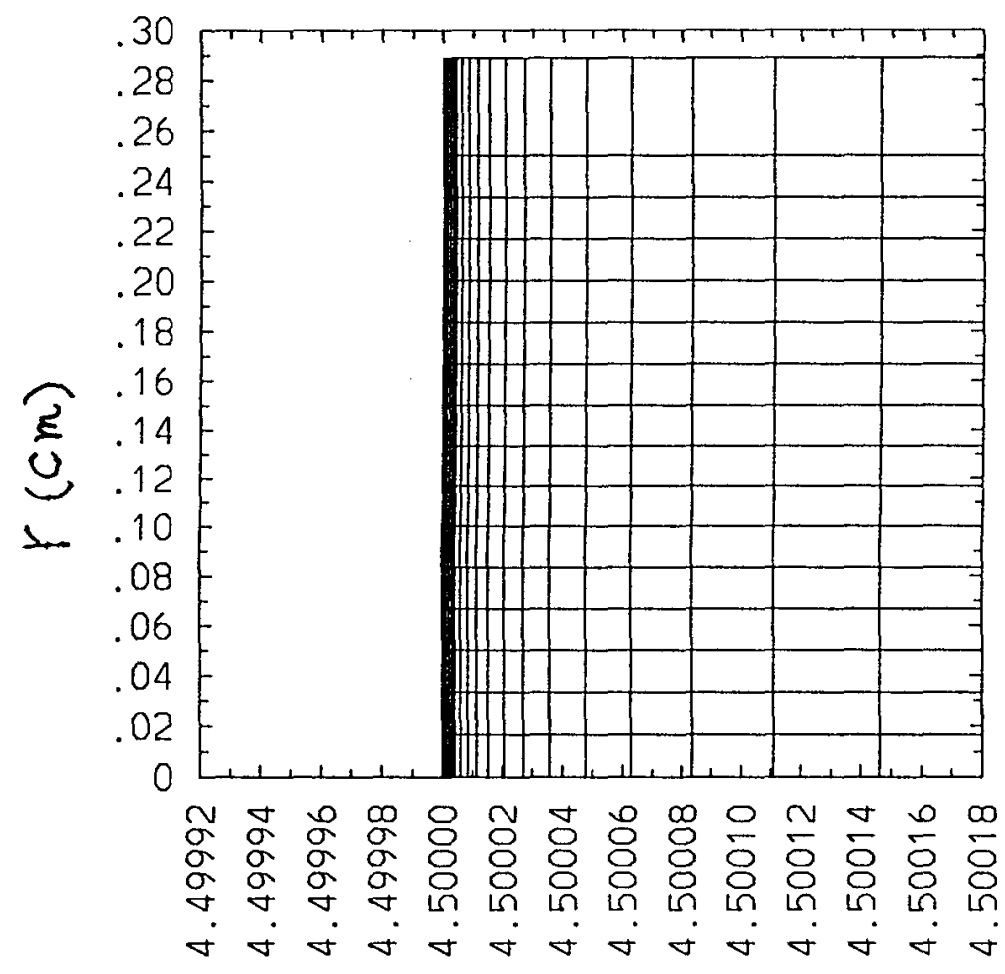

$z(\mathrm{~cm})$

Fig. 2 


$$
t=20 \mathrm{~ns}
$$

(a)

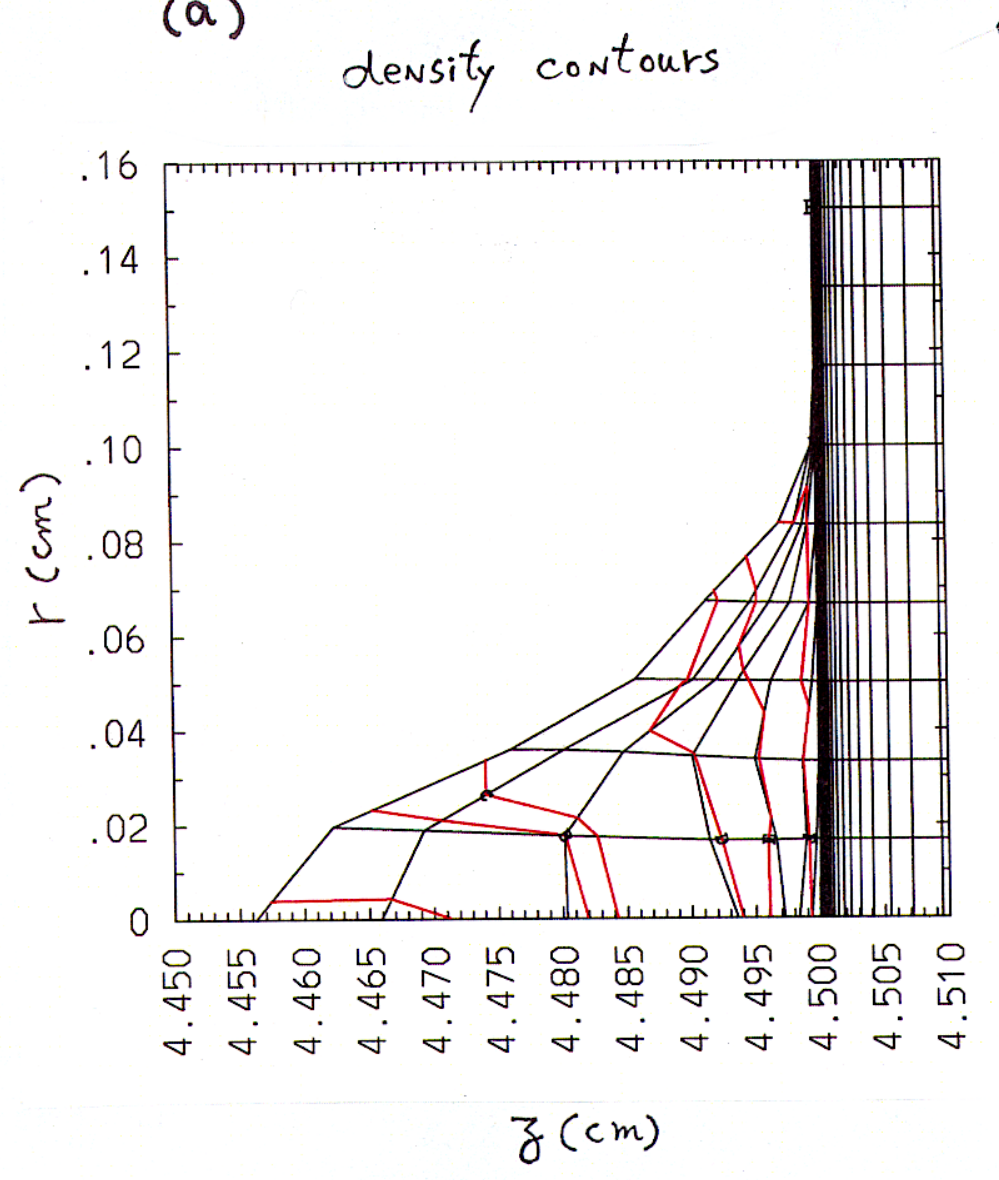

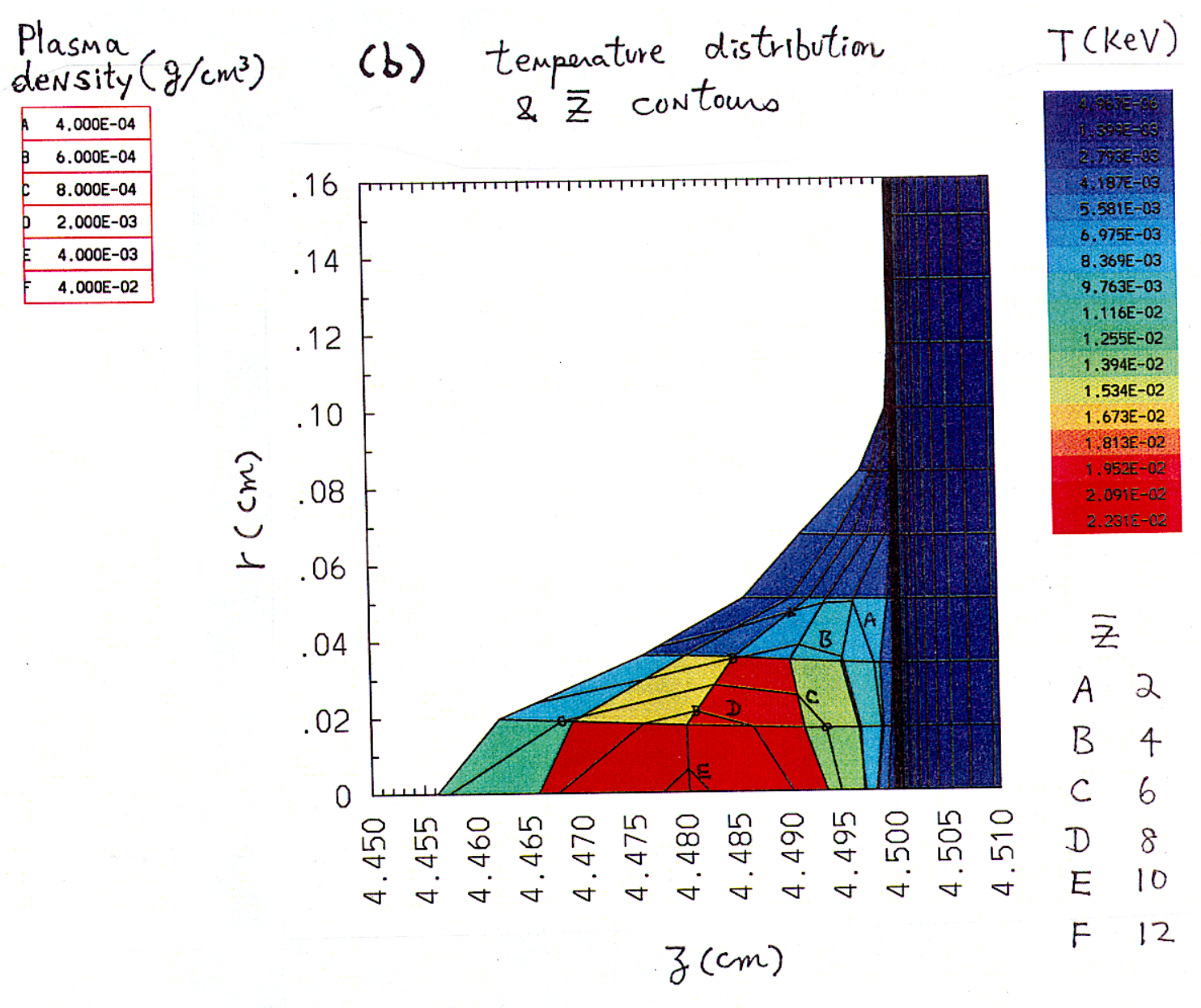

Fig. 3 


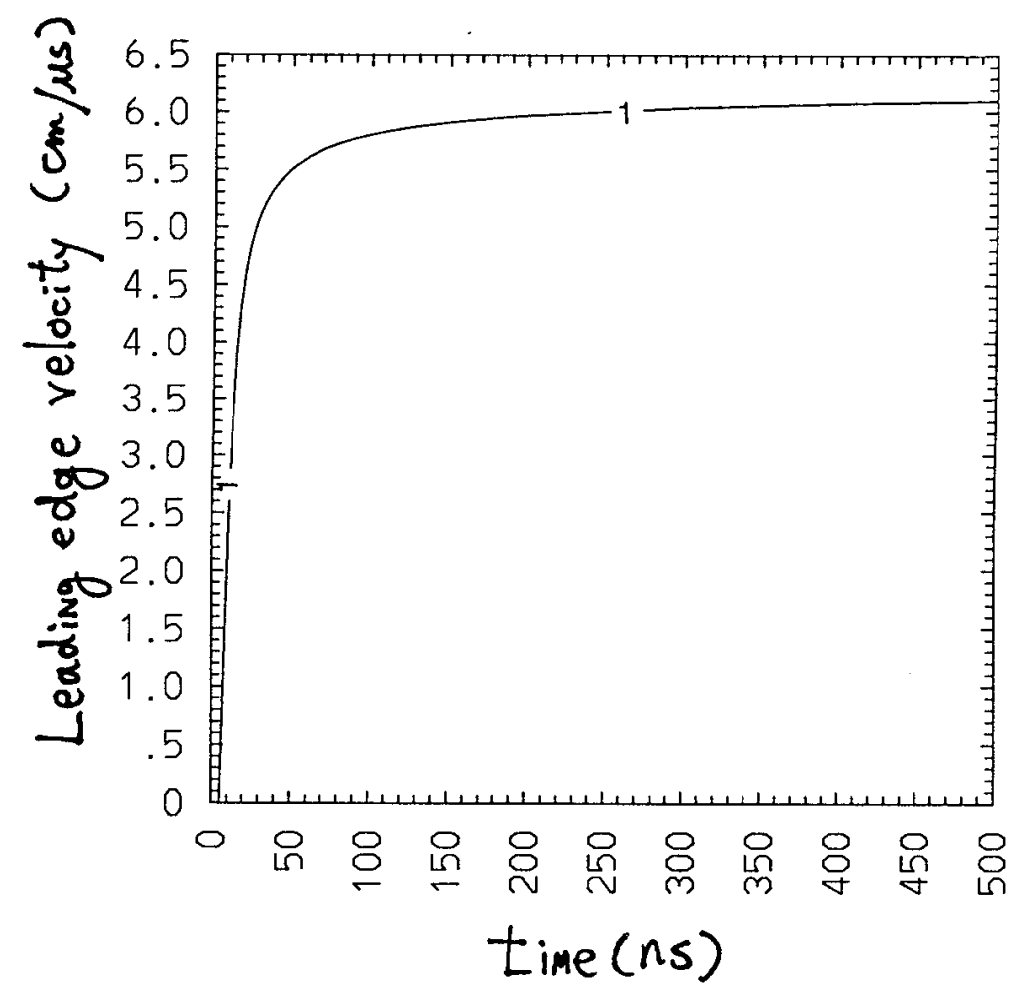

Fig. 4 


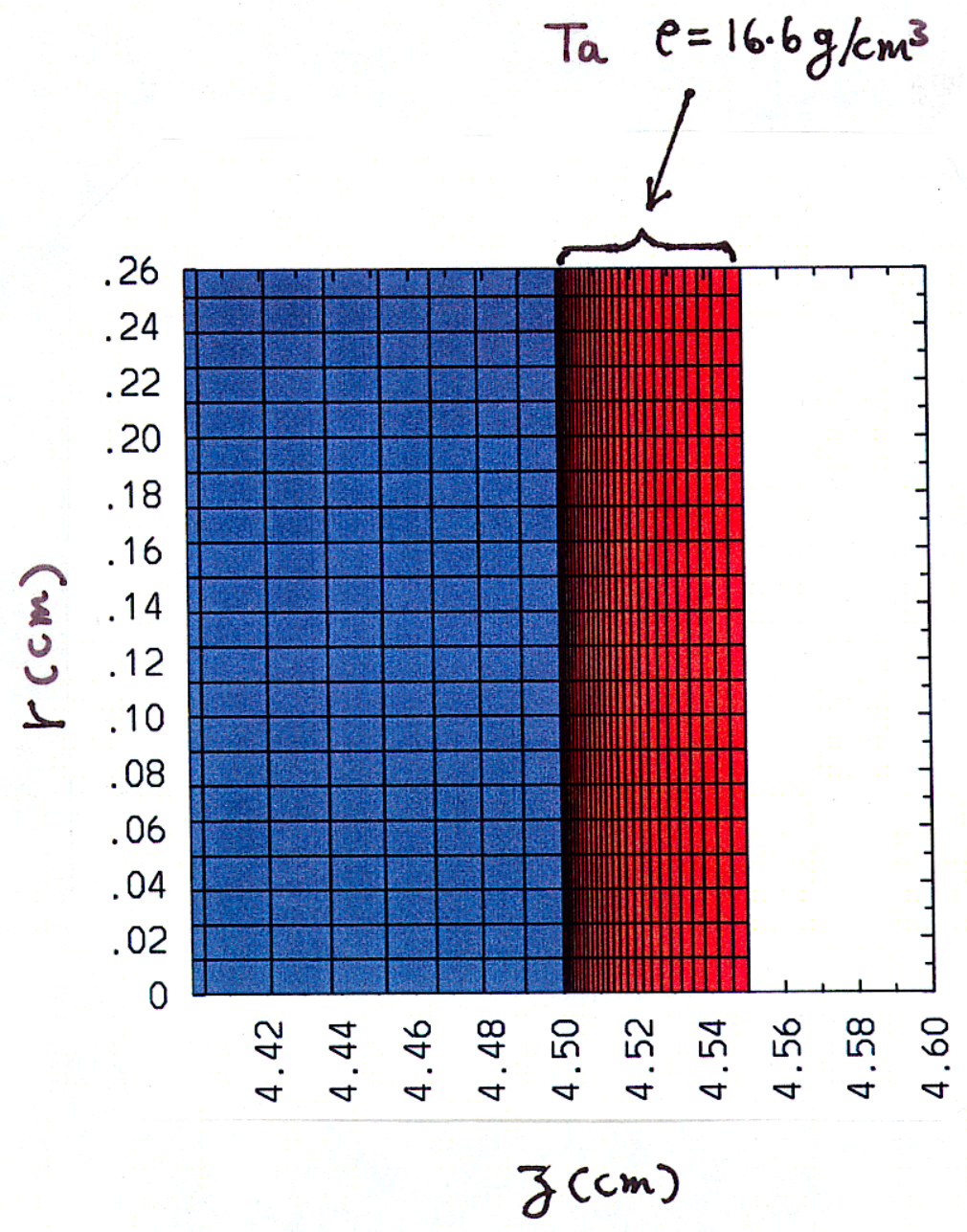

Fig. 5 

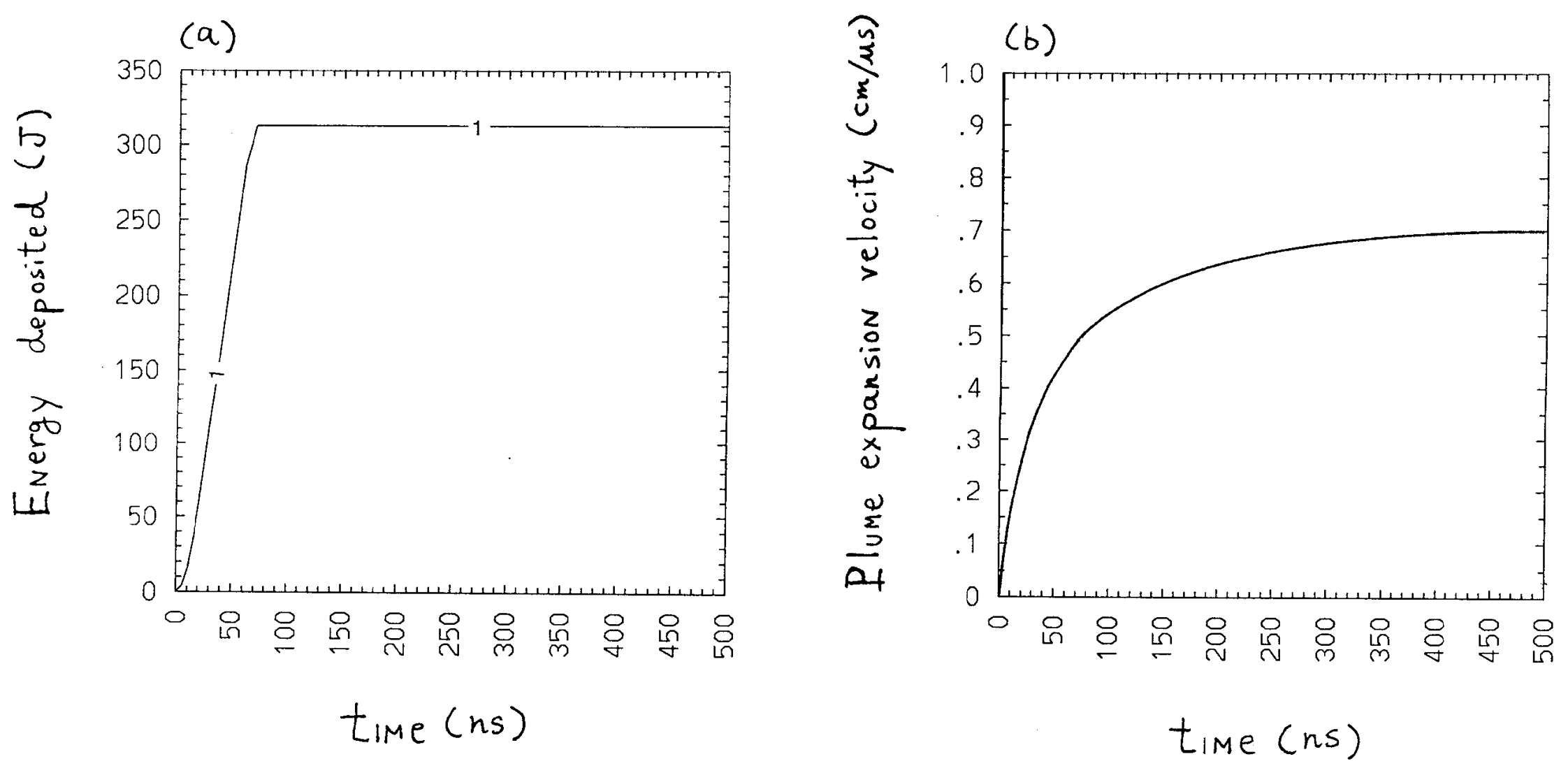

Fig. 6 

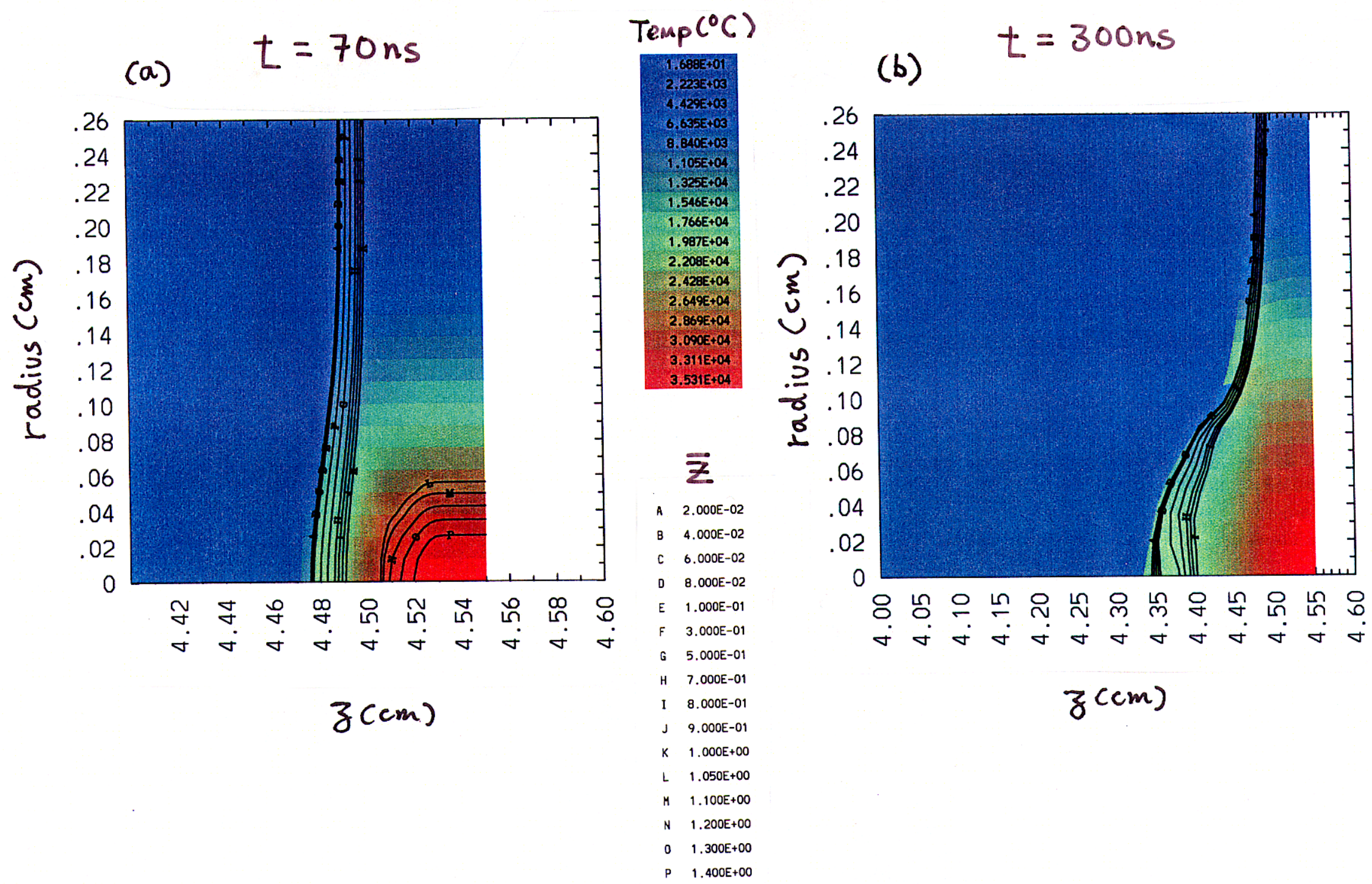

Temp $\left({ }^{\circ} \mathrm{C}\right)$

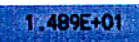

$1.489 z+01$
$1.1300+03$

$1.130 E+03$
$2.246 E+03$

$3.361 \mathrm{E}+03$

$4.476 E+03$

$5.592 E+03$

7. $8222 E+03$

$7.822 E+03$
$8.938 E+03$

$1.005 E+04$

$1.117 E+04$

$.228 E+04$

$340 E+04$

1. $451 \mathrm{E}+04$

1. $563 E+04$

$1.675 E+04$

$\bar{z}$

A 2.000 E- 02

A. $4.000 \mathrm{E}-02$

C $6.000 \mathrm{E}-02$

D.000E-02

E $1.000 \mathrm{E}-01$

F 3.000E-01

G $\quad 5.000 E-01$

H 7.000E-01

I $8.000 \mathrm{E}-01$

J $9.000 \mathrm{E}-01$

K $\quad 1.000 E+00$

L $1.050 E+00$

H. $1.100 E+00$

N $1.200 E+00$

O $1.300 E+00$

P $1.400 E+00$

Fig. 7 
Leading edge velocity of plume vs spot radius

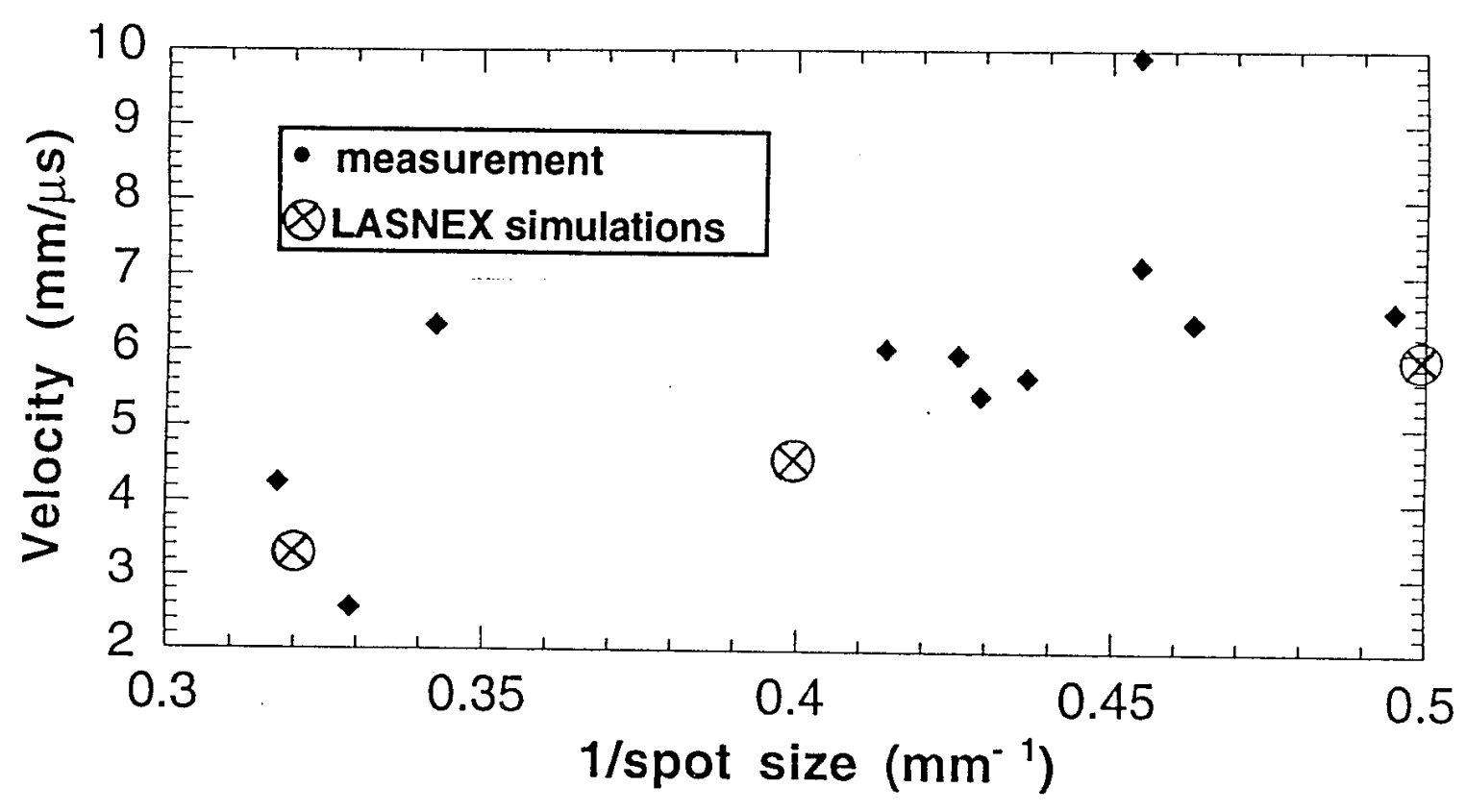

Fig. 8 